\title{
A Novel Approach to Teaching Undergraduates the Societal Impact of Robotics
}

\author{
Ian D. Walker, Pamela E. Mack, and Richard E. Groff
}

\begin{abstract}
Robotics is increasingly impacting the lives of ordinary people worldwide. However, the development and deployment of robots have generally been determined by a select group of engineers and decision makers. In this paper, we describe an innovative undergraduate level course, which focuses on the relationship between society and robotics, and the role society can and should play in the development of robots. The course provides students with credit in Science, Technology, and Society (STS) requirements and broadens their skills in Critical Thinking.
\end{abstract}

Index Terms-Robotics, education, society, critical thinking.

\section{INTRODUCTION}

Robotics and automation play an increasing role in our lives, from manufacturing to robotic surgery. An important question for society is: "What social and ethical questions do robots raise?"

In this paper, we describe a new and innovative undergraduate class, Robots in Business and Society. The course is suitable for non-traditional students for the subject material, notably non-engineering majors. The underlying goal is to educate non-specialist students on the interrelationship between technology and society [1], and better prepare them for making decisions as citizens on the use of robots, now and in the future.

The course guides the student through the technologies that are used to build robots and the capabilities of robots in current applications. The course material guides students in discussing questions such as "How does the Roomba robot clean the floor in a house?" The course explores the economics of robots and the implications of their use as a tool to boost productivity. The future of robots as either an adversary to or equal partner with humanity has been portrayed in movies and books; the course analyzes emerging trends to develop students analyze critically and make their own predictions for the future.

The paper is organized as follows. In the following section, we describe the background leading to the creation of the class, along with the current motivation and vision for it. Section III describes the topics covered in the course, as well as the course organization. Opportunities presented by the material to provide its students with credit in Science,

Manuscript received June 10, 2016; revised August 23, 2016. This work was supported in part by the U.S. National Science Foundation under Grant DUE: TUES number 1245250 .

I. D. Walker and R. E. Groff are with the Department of Electrical and Computer Engineering, Clemson University, Clemson SC 29634 USA (e-mail: iwalker, regroff@clemson.edu).

P. E. Mack is with the Department of History, Clemson University, Clemson SC 29634 USA (e-mail: pammack@ clemson.edu).
Technology and Society (STS) and skills in critical thinking are presented in Section IV. Some observations from a specific class offering are presented in Section V, with conclusions given in Section V.

\section{BACKGROUND AND COURSE MOTIVATION}

\section{A. Background}

The course was created in response to an established need for general competencies in ethics, science, and technology $[2,3]$. The underlying goal is to "motivate students to be inquisitive about the broader implications of science and technology and give them tools to analyze the potential pros and cons of emerging ideas" [3]. The above goal is fairly widely held. However, the development and delivery of suitable course material to achieve them remains a topic of research.

Robotics is a timely topic of widespread potential impact with which to focus education of students of all ages and backgrounds [4-7]. Robots are featured extensively in media and movies, and most people have formed strong impressions of robots and their potential impact on society based on these informal inputs. These impressions are often misleading. Movies and fiction, by their nature, tend to overdramatize the likely impact of robots, and make overly pessimistic predictions. However, robots do have the potential to significantly alter all our lives and are a representative example of a potentially pervasive emerging technology which presents social and ethical issues.

\section{B. Initial Vision}

The initial concept for the class was to teach it as a "hands-on" experience, using Lego robot kits [8] and having student build simple robots [3]. The requirement for students to have hardware imposed significant logistical constraints on another key course goal: online delivery, to make the course accessible to students at universities throughout the world. Therefore ultimately it was decided not to implement the hands-on concept.

\section{Course Development}

The course has been developed, and is co-taught, by two faculty members in Electrical and Computer Engineering and one faculty member in History (the authors of this paper) at Clemson University. The course is offered through the department of Electrical and Computer Engineering as $\boldsymbol{E C} \boldsymbol{E}$ 1010: Robots in Business and Society. It has been created to enable online delivery as part of the established online course program at Clemson University. Undergraduates at any level are eligible to enroll. A flyer used to advertise the course is shown in Fig. 1. 


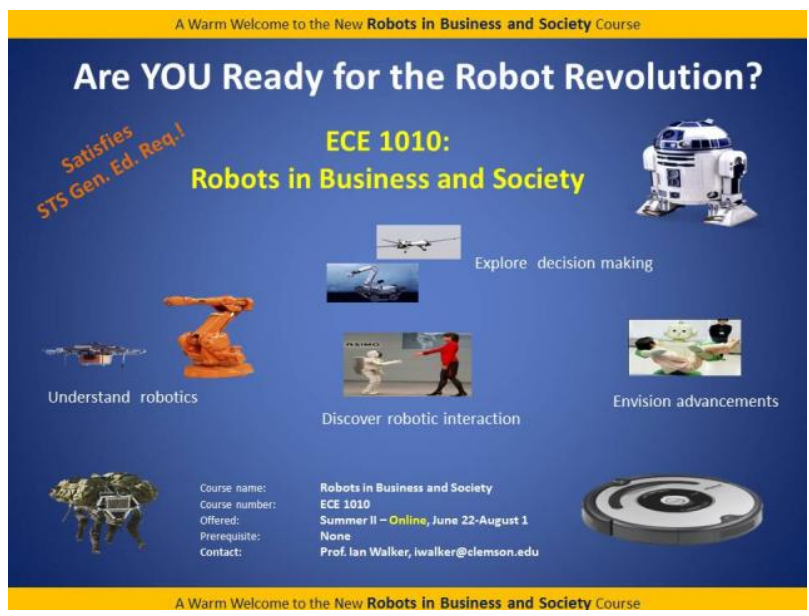

Fig. 1. Flyer advertising the course.

\section{COURSE Structure AND TOPICS}

\section{A. Class Organization}

Each class topical module (for a list and description of topics, see section III.B) consists of three elements: a robot lecture component, a faculty discussion component, and a student/faculty discussion/writing component. In the robot lecture component, underlying technologies, capabilities, and the state of the art in robotics in the specific topic are covered. Each topic also feature discussion among the instructors (the authors of this paper) on wider societal issues related to robots, corresponding to the same topic. Aspects covered include the history and possible future of robots within the given topic, as well as related economic, ethical and legal issues. The lectures and instructor discussions are pre-recorded and made available to the student on Canvas.

The third component of each topical module features discussions involving all students and instructors. There are hosted on Canvas. In class discussions (as well as the exams, and projects), students are expected not only to present and discuss their opinions and conclusions, but also reflect on how and why they have arrived at them: what other choices were possible, what the rationale for the choices made was, etc..

In addition to the above, there are two exams; a midterm and a final, as well as a class project, in which the student chooses one of the topics and explores expands on it in more detail, in response to a given prompt.

\section{B. Topics}

Delivery of the class is structured around the following topics:

1) Introduction. History of robots. How have robots have been developed previously, and to what extent has the public been involved/informed in their use? How do today's robots work? What technologies do they use? Introduction to ethics.

2) Robots and Business. Why do we have ATMs but not robots taking our money in McDonalds? When is it a good business decision to replace humans with machines? What lessons have been learned from using robots on automobile assembly lines? What effect has perception of job losses had on the evolution of robotics?
If robots eventually become so effective that jobs are not replaced with other jobs, how will society react? Robots on the assembly line as a retrospective technology assessment model for what their papers should do.

3) Robots and Transportation. Driverless cars are becoming a reality. How should they be regulated and insured? Will/should we put ourselves in robot cars which might decide to crash and kill us to avoid running into and killing a larger number of other people? Will we want to own our own cars or just summon a car to come to us when we need one?

4) Robots in the Home. With robots like the Roomba vacuum cleaner and "smart homes", we are beginning to live with and within robots. How much could/should our surrounding physical environments become "robots for living in"?

5) Healthcare Robots. Many people envision future robots as caregivers for the elderly. What are the advantages and disadvantages of robots as caregivers? What choices do we have in who/what cares for us? Why might different countries make different choices?

6) Military Applications of Robots. Drones are being used as a key element in today's U.S. military strategy. What public consultation process, if any, has been adopted prior to deployment of this technology? Should military robots that make their own decisions rather than being remotely controlled by a human be allowed to carry weapons? What are the ethical considerations involved in arming robots?

7) Space Robots. Would it be better to send robots into space instead of people? To what extent are scientific spacecraft already robots? What can we learn from the space program about the potential of robots that partly make their own decisions and partly are remotely guided by humans?

8) Robots and Security. Robots are being used today for covert surveillance. How might they be used by governments to monitor and control their populations? What are the limits of the technological fix (the hope that technology will give us easy answers to hard social problems)? Consider the vulnerability of current systems, such as the power grid, water systems etc. How does this project forward to robotics when they are much more prevalent in our lives? As robots play an increasing role in our lives might they be used against us.

9) Our Future with Robots. What could future human/robot worlds look like - should they come to pass? At what point should robots have rights? Will we become robots? How many robot parts can a human being have and still be human? Could/should our consciousness be "uploaded" into robots to extend our lives indefinitely? What would this mean for humanity? How accurate have fiction and futurists proved in predicting the future of robots so far? Is the direction in which technology develops inevitable, or do we have choices?

Each of these topics areas features lecture and discussion components, as noted in section III.A. For 
example, in the "Robots in the Home" module, students will have access to two videos online: (1) a video lecture, featuring one of the course instructors introducing the state of the art in home robotics, and introducing the related potential social issues; and (2) a video of the three instructors debating the issues. For this topic, issues include what robot systems consumers will accept in the home, what information about the home and its occupants can/should/will be sensed and stored by the robots, what choice the occupants have in this, and whether homes could ultimately effectively become prisons for certain classes of occupants (the mentally ill, elderly, etc.).

Having accessed and viewed the above videos, students proceed to a group discussion board (currently using the Canvas system), in which they debate the related issues with their fellow students, the class Teaching Assistant, and the instructors. A reading to promote thinking for the discussion, a short story by J.G. Ballard [9], is accessible to the students online. Students are expected to display aspects of critical thinking (see section IV.A) during the discussions.

Similarly, in the "Healthcare Robots" module, the students are given online access to two videos: a class lecture and instructor debate. They then proceed to the online discussion board for active participation. Issues here include how the attitudes of different societies may lead to different answers to whether robots should be deployed to take care of their elderly populations, whether robot care givers in the home will collect information about the human occupants, and who should/will have access to that information. A reading discussing these issues [10] is accessible online.

In general, the following questions will be asked, subject to their particular relevance for the given topic of each given module:

- CHOICE--what choices are being made and who is doing the choosing?

- ACCESS - who will have access to the technology (and knowledge about its results)?

- RISK--what risks are involved and how they are defined, measured, and weighed?

- COST--what costs (economic, environmental, social, etc.) are involved?

- RESPONSIBILITY - who is responsible if harm results?

BENEFITS-- what the benefits of the various options are; whether the benefits are widely or narrowly distributed; whether the same people who get the benefits also suffer the risks.

\section{CRitical Thinking, General Education, AND ASSESSMENT}

\section{A. Critical Thinking}

In their future careers as business leaders, educators, physicians, etc., students will make important decisions about robotics; the course is intended to enhance critical thinking tools they need to make good decisions. The course aligns with Clemson University's Thinks ${ }^{2}$ Quality
Enhancement

Plan

(http://www.clemson.edu/assessment/thinks2/), an ambitious experiment in critical thinking that aspires to transform student learning and faculty teaching across the curriculum and in the disciplines. The course is structured to require and improve elements of critical thinking [11]. Students are expected throughout the class not only to analyze and make decisions about technology, but also to question and reason about their related assumptions and conclusions. The required research project functions as an artifact representative of critical thinking.

We will use the California Critical Thinking Skills Test (CCST) [12], [13] to evaluate and monitor student growth in critical thinking. The test is administered twice: at the beginning and toward the end of the course. The results of these tests do not count toward course grades or degree progress at Clemson and only aggregate results are used to evaluate the teaching strategies of this course versus other courses.

Student Learning Outcomes

With respect to critical thinking, the successful student should demonstrate the ability to satisfy the following four Student learning Outcomes (SLO's):

SLO1: Analyze complex problems to identify and evaluate robotic solutions to them

SLO2: Separate relevant from irrelevant technologies for realization of proposed robot solutions to problems

SLO3: Assess alternative solutions for robots on both technical and social grounds

SLO4: Communicate complex ideas effectively

The relationships of the above outcomes to Clemson's official set of CT2 Program outcomes, together with the specific aspects of the course topics they are related to, are illustrated in Table I.

TABLE I: CRITICAL THINKING OUTCOMES

\begin{tabular}{|c|c|c|}
\hline $\begin{array}{ll}\text { Student } & \text { Learning } \\
\text { Outcome } & \\
\end{array}$ & $\begin{array}{l}\text { Associated Class } \\
\text { Project Activity }\end{array}$ & $\begin{array}{l}\text { Clemson CT2 } \\
\text { Program Outcome }\end{array}$ \\
\hline $\begin{array}{l}\text { SLO1: Analyze } \\
\text { complex problems to } \\
\text { identify and evaluate } \\
\text { robotic solutions to } \\
\text { them and whether } \\
\text { technical solutions } \\
\text { are appropriate at all. }\end{array}$ & $\begin{array}{l}\text { Identify features in the } \\
\text { world that need to be } \\
\text { known and modified to } \\
\text { address a given real } \\
\text { world problem with } \\
\text { robots. } \\
\text { Identify and evaluate } \\
\text { potential ethical issues } \\
\text { arising from robot } \\
\text { solutions to given real } \\
\text { world problem. }\end{array}$ & $\begin{array}{l}\text { Explore } \quad \text { Complex } \\
\text { Challenges }\end{array}$ \\
\hline $\begin{array}{lr}\text { SLO2: } & \text { Separate } \\
\text { relevant } & \text { from } \\
\text { irrelevant } & \\
\text { technologies } & \text { for } \\
\text { realization } & \text { of } \\
\text { proposed } & \text { robot } \\
\text { solutions to problems }\end{array}$ & $\begin{array}{l}\text { Identify feasible } \\
\text { combinations of } \\
\text { actuation and sensing } \\
\text { for proposed robot } \\
\text { solutions to real world } \\
\text { problems. }\end{array}$ & $\begin{array}{l}\text { Analyze } \\
\text { Multi-dimensional } \\
\text { Problems }\end{array}$ \\
\hline $\begin{array}{l}\text { SLO3: } \\
\text { alternative solutions } \\
\text { for robot designs }\end{array}$ & $\begin{array}{l}\text { Propose and critique } \\
\text { alternative designs. }\end{array}$ & $\begin{array}{l}\text { Synthesize Alternative } \\
\text { Solutions to } \\
\text { Multi-Dimensional } \\
\text { Challenges }\end{array}$ \\
\hline $\begin{array}{l}\text { SLO4: Communicate } \\
\text { effectively complex } \\
\text { ideas }\end{array}$ & $\begin{array}{l}\text { Create a clear and } \\
\text { concise project report, } \\
\text { complete with analysis } \\
\text { and recommendations. }\end{array}$ & $\begin{array}{l}\text { Communicate } \\
\text { effectively complex } \\
\text { ideas }\end{array}$ \\
\hline
\end{tabular}

The ability of students to develop and demonstrate the skills needed to achieve these outcomes is an important part 
of the criteria used to establish their grade for the discussions and course project (see section IV.C).

\section{B. Science and Technology in Society}

This course meets the general education requirement at Clemson University in Science and Technology in Society (STS) [14], [15]:

Demonstrate an understanding of issues created by the complex interactions among science, technology, and society.

The required research paper is the students STS artifact. While students are no longer required to upload artifacts to an ePortfolio at Clemson, the university will be collecting artifacts from general education courses to evaluate general education.

We use the Views on Science and Technology Survey (VOSTS) instrument [16], [17] to evaluate and monitor student growth in attitudes to science and technology. The test is administered twice: at the beginning and toward the end of the course. The results of these tests do not count toward course grades or degree progress at Clemson and only aggregate results are used to evaluate the teaching strategies of this course versus other courses.

\section{Assessment}

The following standard grading scale applies; $\geq 90=\mathrm{A}, 90-80=\mathrm{B}, 80-70=\mathrm{C}, 70-60=\mathrm{D},<60=\mathrm{F}$ $20 \%$ Participation

$30 \%$ Research project (initial discussion 10\%, research paper $20 \%$ )

\section{$20 \%$ Midterm exam}

$30 \%$ Final exam

Criteria for grading: percentage correct on exams (problems examine knowledge of types, operation, and applications of robots as covered in class lectures); and success in meeting Student Learning Outcomes (see section IV.A) on research project. The use of critical thinking in meeting the Student Learning Objectives in working on and discussing the projects is necessary, and is stimulated during class discussions via questions such as:

What is the central issue/problem? (For example in meeting SLO1)

How did you reason out this issue? Why do you think that was the best solution? (For example in meeting SLO2)

What is/are the evidence/arguments pro and con? How did you come to that interpretation? (In meeting SLO3)

What are you claiming/concluding? Why did you make this claim/come to this conclusion? (In meeting SLO4)

\section{INITIAL OFFERING}

The course was first offered, as an online class, in summer 2016. The course period was six weeks. Majors of the students enrolled were Agricultural Education, Bioscience, Civil Engineering, Electrical Engineering, General Engineering, Industrial Engineering, and Science Teaching. Student experience levels ranged from freshmen (first year) to senior (fourth year). There was a $50 \% / 50 \%$ split between female and male students enrolled in the course. The ratio between engineering and non-engineering major enrollees was $63 \% / 37 \%$.

The discussion board approach to engaging students proved effective. It was clear that the students were engaged and benefiting from the perspectives of each other. Two interesting and representative example posts are reproduced below:

(On driverless cars): I enjoyed reading your point! More now than ever, people enjoy adrenaline and convenience. I feel that driverless cars offer both of these things and could have the potential to catch on. I also enjoyed reading about your benefits listed. Those are factors that I had not considered when writing my discussion post. If technology were controlling the car, it could potentially be a better and more safe driver than those driving now.

(On security issues related to driverless cars): I didn't even think of an example like identity theft, though it is very true. The risks of identity theft haven't preventing everyone from sharing personal information on the web. Also, things like Apple Pay have a great security risk inherently involved with them. Yet, people use Apple Pay and other apps similar on a daily basis. I don't believe there will be a large amount of security risks involved in driverless cars. And no matter the risks that are involved, people (in general) are always more interested in the newest technology that simplifies their lives. The only thing that may make some wary of driverless cars is the risk of them being hijacked. One hijacked driverless car could cause an accident of epic proportions. However, I believe this risk could be avoided with a simple override switch. The switch would relinquish control from the robot to the human. A simple fix to a problem that could destroy lives, buildings, and futures.

The structure of the class proved sufficiently flexible to accommodate modifications to the discussion board topics, to reflect new and emerging relevant topics. For example, during the delivery of the class, the first example of a robot being used by police to actively kill a human (an active shooter) occurred [18]. To acknowledge this event, and to allow the students in the class to reflect on and discuss the event and its implications, a new and separate discussion board topic was created.

An issue encountered in the initial offering included the difficulty of teaching critical thinking in an online course. While there are numerous alternative definitions for critical thinking [19]-[21], most of them center on some form of self-reflection, typically manifested by offering not only an opinion on a subject, but also justifying why that given opinion is held. While the discussion board activities were helpful - and were the main form used to evaluate critical thinking in the students - the instructors found it difficult to promote critical thinking when the students and instructors were not co-located, and it was not possible to give immediate live feedback or know they had the continuous attention of the students in order to walk them carefully through a series of steps.

\section{CONCLUSION}

We have described and discussed a new undergraduate course, Robots in Business and Society. The key innovation underlying the class is its involvement of non-traditional students, i.e. non-engineering majors, and their engagement in issues related to robotics and its impact on society. Currently, the authors are collecting and evaluating test and survey data from multiple offerings of the class, to evaluate the impact of the course in improving student skills in critical 
thinking and attitudes to science and technology.

\section{REFERENCES}

[1] S. H. Cutcliffe, Ideas, Machines and Values: An Introduction to Science, Technology, and Society Studies, Rowman \& Littlefield Publishers, 2000.

[2] D. W. Cheek, Thinking Constructively About Science, Technology, and Society Education: General Introduction and From the Creation to the Flood, Suny Press, 1992.

[3] T. Burg, P. Mack, I. Walker, and R. Groff, "Building and assessing a hands-on learning experience for robots in business and society," in Proc. the ASEE Zone III Conference, Springfield, MO, pp. 1-10, September 2015.

[4] A. Kapadia, I. D. Walker, K. E. Green, J. C. Manganelli, H. Houayek, A. James, V. K. T. Kanuri, T. Mokhtar, and P. Yanik, "Rethinking the machines in which we live: A multidisciplinary course in architectural robotics," IEEE Robotics and Automation Magazine, September 2014, pp. 143-150.

[5] R. Manseur, "Development of an undergraduate robotics course," in Proc. the 27th Annual Conference on Teaching and Learning in an Era of Change, vol. 2, 1997.

[6] M. J. Mataric, "Robotics education for all ages," in Proc. AAAI Spring Symposium on Accessible, Hands-on AI and Robotics Education, 2004

[7] I. R. Nourbakhsh, K. Crowley, A. Bhave, E. Hamner, T. Hsiu, A. Perez-Bergquist, S. Richards, and K. Wilkinson, "The robotic autonomy mobile robotics course: Robot design, curriculum design and educational assessment," Autonomous Robots, vol. 18, no. 1, pp. 103-127, 2005.

[8] E. Z. F. Liu, C. H. Lin, C. H. and C. S. Chang, "Student satisfaction and self-efficacy in a cooperative robotics course," Social Behavior and Personality: An International Journal, vol. 38, no. 8, pp. 1135-1146, 2010.

[9] J. G. Ballard, Thousand Dreams of Stellavista, Short Story, 1963.

[10] A. Sharkey and N. Sharkey, "Granny and the robots," Ethics and Information Technology, vol. 14, issue 1, pp. 27-40, March 2012.

[11] P. Facione and C. A. Gittens, Think Critically, Pearson Education Inc., 2016.

[12] California critical thinking skills test. [Online]. Available: http://www.insightassessment.com/About-Us/California-Critical-Thin king-Skills-Test-Family

[13] P. A. Facione, "Using the california critical thinking skills test in research, evaluation, and assessment," 1991.

[14] P .E. Mack, T. Campbell, and N. H. Abd-Hamid, "Issues in survey assessments of STS courses," Bulletin of Science, Technology, and Society, vol. 28, pp. 408-413, October 2008.

[15] E. Pedretti, "Teaching science, technology, society and environment (STSE) education," The Role of Moral Reasoning on Sociocientific Issues and Discourse in Science Education, Springer Netherlands, pp. 219-239, 2003

[16] G.S. Aikenhead and A.G. Ryan, "The development of a new instrument: Views on science-technology-society (VOSTS)," Sci. Ed., vol. 76, 1992, pp. 477-491, 1992

[17] VOSTS survey. [Online]. Available: http://www.flaguide.org/tools/attitude/views_science_tech.php

[18] H. Fountain and M. S. Schmidt, "'Bomb robot' takes down dallas gunman, but raises enforcement questions," New York Times, July 8 2016.
[19] R. H. Ennis, "A taxonomy of critical thinking dispositions and abilities," 1987.

[20] P.A. Facione, "Critical thinking: A statement of expert consensus for purposes of educational assessment and instruction, research findings and recommendations," 1990.

[21] D. F. Halpern, Thought and Knowledge: An Introduction to Critical Thinking, Routledge, 2002.

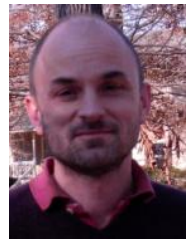

Ian D. Walker received the B.Sc. degree in mathematics from the University of Hull, England, in 1983, and the M.S. and Ph.D., degrees, both in electrical and computer engineering, from the University of Texas, Austin, in 1986 and 1989 , respectively.

He is currently a professor of electrical and computer engineering at Clemson University in South Carolina, USA. Previously he has been an assistant professor and an associate professor at Rice University in Houston, Texas, USA. He has authored or co-authored more than two hundred reviewed publications. His research interest are in the area of robotics.

Prof. Walker is a fellow of the Institute of Electrical and Electronics Engineers (IEEE) and an associate fellow of the American Institute of Aeronautics and Astronautics (AIAA)

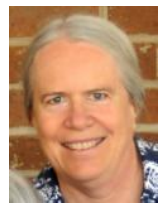

Pamela E. Mack received the A.B. degree from Harvard University, Cambridge MA, in history of science in 1977 and the Ph.D. from University of Pennsylvania, Philadelphia PA, in history and sociology of science and technology in 1985.

She is currently an associate professor of history and coordinator of the Science and Technology in Society Program at Clemson University in Clemson, South Carolina. Previously she taught at Virginia Tech, Hampshire College, and Worcester Polytechnic and held a fellowship at the National Air and Space Museum. Her research has been in history of the US space program, history of forestry, history of women in science and engineering, and pedagogy for science and technology in society.

Prof. Mack has been most involved in the history of science society and the Society for the History of Technology. She won the History of Science Society's Joseph H. Hazen Education Prize, for outstanding contributions to the teaching of history of science in 2005.

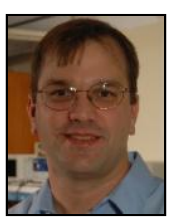

Richard E. Groff received B.S. degrees from the Pennsylvania State University, State College, PA, in engineering science and mechanics and German in 1996, and received the M.S. and Ph.D. from University of Michigan, Ann Arbor, Michigan, in electrical engineering and computer science in 1998 and 2003, respectively.

$\mathrm{He}$ is currently an associate professor of electrical and computer engineering at Clemson University in Clemson, SC. Previously he was a postdoctoral fellow at University of California, Berkeley. His research interests are in the area of controls and robotics with a focus on biomedical applications.

Prof. Groff is a member of the Institute of Electrical and Electronics Engineers (IEEE), the ASME, and American Society for Engineering Education (ASEE). 